\title{
Heart rate dynamics after exercise in cardiac patients with and without type 2 diabetes
}

\section{Victor R. Neves ${ }^{1,2}$, Antti M. Kiviniemi ${ }^{1}$, Arto J. Hautala ${ }^{1}$, Jaana Karjalainen ${ }^{3}$, Olli-Pekka Piira ${ }^{3}$, Aparecida M. Catai ${ }^{2}$, Timo H. Mäkikallio ${ }^{3}$, Heikki Veli Huikuri ${ }^{3}$ and Mikko P. Tulppo ${ }^{1,3}$ *}

\author{
1 Department of Exercise and Medical Physiology, Verve, Oulu, Finland \\ 2 Department of Physiotherapy, Federal University of São Carlos, São Carlos, Brazil \\ ${ }^{3}$ Department of Internal Medicine, Institute of Clinical Medicine, University of Oulu, Oulu, Finland
}

\section{Edited by:}

Jaakko Hartiala, Turku University

Hospital, Finland

\section{Reviewed by:}

Antti Saraste, University of Turku, Finland

Petri Haapalahti, HUSLAB, Finland

Tomi Laitinen, University of Eastern

Finland and Kuopio University

Hospital, Finland

\section{*Correspondence:}

Mikko P. Tulppo, Department of Exercise and Medical Physiology, Verve, P.O. Box 404, Fl-90101 Oulu, Finland.

e-mail:mikko.tulppo@verve.fi
Purpose: The incidence of cardiovascular events is higher in coronary artery disease patients with type 2 diabetes (CAD +T2D) than in CAD patients without T2D. There is increasing evidence that the recovery phase after exercise is a vulnerable phase for various cardiovascular events. We hypothesized that autonomic regulation differs in CAD patients with and without T2D during post-exercise condition. Methods: A symptomlimited maximal exercise test on a bicycle ergometer was performed for $68 \mathrm{CAD}+\mathrm{T} 2 \mathrm{D}$ patients (age $61 \pm 5$ years, $78 \%$ males, ejection fraction (EF) $67 \pm 8,100 \%$ on $\beta$-blockade), and 64 CAD patients (age $62 \pm 5$ years, $80 \%$ males, EF $64 \pm 8,100 \%$ on $\beta$-blockade). Heart rate $(H R)$ recovery after exercise was calculated as the slope of $H R$ during the first $60 \mathrm{~s}$ after cessation of exercise $\left(H R R_{\text {slope }}\right)$. R-R intervals were measured before $(5 \mathrm{~min})$ and after exercise from 3 to $8 \mathrm{~min}$, both in a supine position. R-R intervals were analyzed using time and frequency methods and a detrended fluctuation method $\left(\alpha_{1}\right)$. Results: BMI was $30 \pm 4$ vs. $27 \pm 3 \mathrm{~kg} \mathrm{~m}^{2}(p<0.001)$; maximal exercise capacity, $6.5 \pm 1.7$ vs. $7.7 \pm 1.9 \mathrm{METs}$ $(p<0.001)$; maximal HR, $128 \pm 19$ vs. $132 \pm 18 \mathrm{bpm}(p=\mathrm{ns})$; and HRR $\mathrm{H}_{\text {slope }},-0.53 \pm 0.17$ vs. $-0.62 \pm 0.15$ beats $/ s(p=0.004)$, for CAD patients with and without T2D, respectively. There was no differences between the groups in HRR slope after adjustment for METs, BMI, and medication (ANCOVA, $p=0.228$ for T2D and, e.g., $p=0.030$ for METs). CAD +T2D patients had a higher HR at rest than non-diabetic patients $(57 \pm 10$ vs. $54 \pm 6 \mathrm{bpm}$, $p=0.030$ ), but no other differences were observed in HR dynamics at rest or in postexercise condition. Conclusion: HR recovery is delayed in CAD +T2D patients, suggesting impairment of vagal activity and/or augmented sympathetic activity after exercise. Blunted HR recovery after exercise in diabetic patients compared with non-diabetic patients is more closely related to low exercise capacity and obesity than to T2D itself.

Keywords: heart rate recovery, type 2 diabetes, autonomic regulation

\section{INTRODUCTION}

The incidence of cardiovascular events is higher in coronary artery disease patients (CAD) with type 2 diabetes (T2D) than in CAD patients without T2D (Haffner et al., 1998; Junttila et al., 2010), but the physiological or pathophysiological mechanisms causing these differences are not well known. Altered autonomic regulation is one potential mechanism resulting in the increased number of cardiovascular events in CAD + T2D patients (Okada et al., 2010; Pop-Busui et al., 2010; Lanza et al., 2011). Autonomic regulation can be studied using various methods at the laboratory, or ambulatory condition tests such as passive head-up tilt and handgrip tests (Montano et al., 1994; Tulppo et al., 2001, 2005; Fu et al., 2002), or ambulatory heart rate (HR) variability and blood pressure measurements (Pagani et al., 1985; Kleiger et al., 1987; Piira et al., 2011). Analysis of autonomic regulation during and after exercise has also been used in various physiological (Yamamoto et al., 1991; Gregoire et al., 1996; Tulppo et al., 1996, 1998b) and clinical settings (Cole et al., 1999, 2000; Jouven and Ducimetiere, 2000; Jouven et al., 2005; Kiviniemi et al., 2011).
There is increasing evidence that the recovery phase after exercise is a vulnerable phase for various cardiovascular events. Casecrossover studies have shown that exercise as a trigger of acute myocardial infarction is not limited to the time of exercise, but extends for a certain time period after cessation of physical activity (Siscovick et al., 1982, 1984; Albert et al., 2000; von Klot et al., 2008). Similarly, the risk of sudden cardiac death is transiently increased in the 30-min after vigorous exercise, and atrial fibrillation episodes occur more commonly after rather than before exercise (Siscovick et al., 1982, 1984; Coumel, 1994; Albert et al., 2000; Huikuri, 2008). Measurement of autonomic function in the very early phase of recovery after exercise has also provided prognostic information. For example, delayed HR recovery 1-2 min after exercise has been shown to predict cardiovascular events in the general population and in various patient groups and animal studies (Cole et al., 1999; Lauer and Froelicher, 2002; Nissinen et al., 2003; Jouven et al., 2005; Smith et al., 2005). Recently, we have shown that co-activation of both autonomic arms may occur during the recovery phase of exercise (Tulppo et al., 2011), which 
may partly explain the clustering of various cardiovascular events in the recovery phase of exercise.

The present research was designed to study the behavior of HR dynamics during exercise and in the recovery phase of exercise in CAD patients with and without T2D, matched for age, ejection fraction (EF), and sex. We hypothesized that autonomic regulation, measured by $H R$ recovery and $H R$ variability methods, differs in CAD patients with and without T2D, particularly during post-exercise condition.

\section{MATERIALS AND METHODS SUBJECTS AND STUDY PROTOCOL}

The present study was conducted in the Department of Exercise and Medical Physiology at Verve (Oulu, Finland) and Oulu University Hospital, and the patients were selected from patients in the ARTEMIS (Innovation to Reduce Cardiovascular Complications of Diabetes at the Intersection) study database who had stable CAD without $(n=64)$ and with T2D $(n=68)$. The exclusion criteria were inability to perform the exercise stress test, unstable angina at the time of recruitment, advanced age ( $>75$ years), a recent ( $<6$ months) myocardial infarction, severe nephropathy, heart failure, scheduled cardiac revascularization therapy, T2D diagnosed less than 6 months from the beginning of study, diabetes autonomic neuropathy, dementia, alcoholism, drug abuse, or any condition that could impair the subject's capacity to give informed consent. CAD was documented by coronary angiography and T2D was verified by oral glucose tolerance test according to current recommendations (WHO, 1999). The study was performed according to the Declaration of Helsinki, the local committees of research ethics in the Northern Ostrobothnia Hospital District (Oulu, Finland) approved the protocol, and all the subjects gave written informed consent.

The laboratory measurements were performed in the Department of Exercise and Medical Physiology at Verve (Oulu, Finland). The patients were not allowed to eat or consume caffeine for $3 \mathrm{~h}$ before the tests. Physical exercise and use of alcohol were prohibited for $24 \mathrm{~h}$ before testing. Electrocardiography (ECG) and R-R intervals were collected for $10 \mathrm{~min}$ at supine rest, during exercise, and $10 \mathrm{~min}$ after exercise in supine position. Breathing was spontaneous in all phases. A capillary blood sample was obtained for analysis of HbA1c concentration before testing (Afinion ${ }^{\mathrm{TM}} \mathrm{AS} 100$, Axis-Shield PoC AS, Oslo, Norway).

\section{EXERCISE STRESS TEST}

The patients performed an incremental maximal test on a bicycle ergometer (Monark Ergomedic 839 E; Monark Exercise AB, Vansbro, Sweden), starting at $30 \mathrm{~W}$ with the work rate increasing at a rate of 10 and $15 \mathrm{~W}$ every $1 \mathrm{~min}$ until exhaustion for females and males, respectively. The patients moved to the supine position within $30 \mathrm{~s}$ after cessation of exercise. The patients were not allowed to move or talk during the recovery phase.

Ventilation $\left(V_{E}\right)$ and gas exchange (M909 Ergospirometer, Medikro, Kuopio, Finland) were measured and reported as the mean value for every minute. The highest 1-min mean value of oxygen consumption was expressed as the peak oxygen consumption $\left(\mathrm{VO}_{2 \text { peak }}\right)$. Maximal workload $(\mathrm{W})$ and maximal METs were calculated as average workload and METs during the last
1 min of the test. ECG was monitored and recorded using a standard 12-lead ECG (GE Healthcare, Cam-14, Waukesha, WI, USA) and at the same time R-R intervals were recorded with a Polar R-R recorder with a sampling frequency of $1,000 \mathrm{~Hz}$ (Polar Electro, Kempele, Finland). Blood pressure was measured with an electronic sphygmomanometer (Tango, Sun-Tech, Raleigh, NC, USA) at rest and during exercise testing. The patients were encouraged to reach a symptom-limited maximal workload, and exercise was stopped if ST depression was $>0.2 \mathrm{mV}$.

The maximal HR was calculated as a mean value of $5 \mathrm{R}-\mathrm{R}$ intervals before cessation of exercise from Polar R-R interval data and converted to maximal $\mathrm{HR}$ in beats/min with the following equation: maximal $\mathrm{HR}$ (beats $/ \mathrm{min})=60 \cdot($ mean $\mathrm{R}-\mathrm{R}$ interval in $\mathrm{ms} / 1000)^{-1}$. The chronotropic response to exercise was calculated by chronotropic response index (CRI) with the following equation: $\mathrm{CRI}=100 \cdot($ maximal $\mathrm{HR}$ - resting $\mathrm{HR}) \cdot(220$ - age - resting $\mathrm{HR})^{-1}$ (Kiviniemi et al., 2011), and HR reserve as maximal $\mathrm{HR}$ - resting $\mathrm{HR}$. HR recovery values were calculated as mean values of $5 \mathrm{R}-\mathrm{R}$ intervals around the time points of $15\left(\mathrm{HRR}_{15}\right)$, $30\left(\mathrm{HRR}_{30}\right), 60\left(\mathrm{HRR}_{60}\right)$, and $120\left(\mathrm{HRR}_{120}\right) \mathrm{s}$ after cessation of exercise from Polar data. Thereafter, HR recovery (beats/min) was calculated as the change in HR from maximal HR to recovery $\mathrm{HR}$ at the time points of $15,30,60$, and $120 \mathrm{~s}$ after cessation of exercise. The slope of HR during the 60-s after cessation of exercise $\left(\mathrm{HRR}_{\text {slope }}\right)$ was calculated by linear model using above described $H R$ values at the maximum and 15, 30, and $60 \mathrm{~s}$ time points (Figure 1).

\section{HEART RATE VARIABILITY}

$\mathrm{R}-\mathrm{R}$ intervals were analyzed from the last 5-min period at rest, at every load during exercise (1-min periods), and from 3 to $8 \mathrm{~min}$ (5-min) after exercise. Before HR variability analysis (using

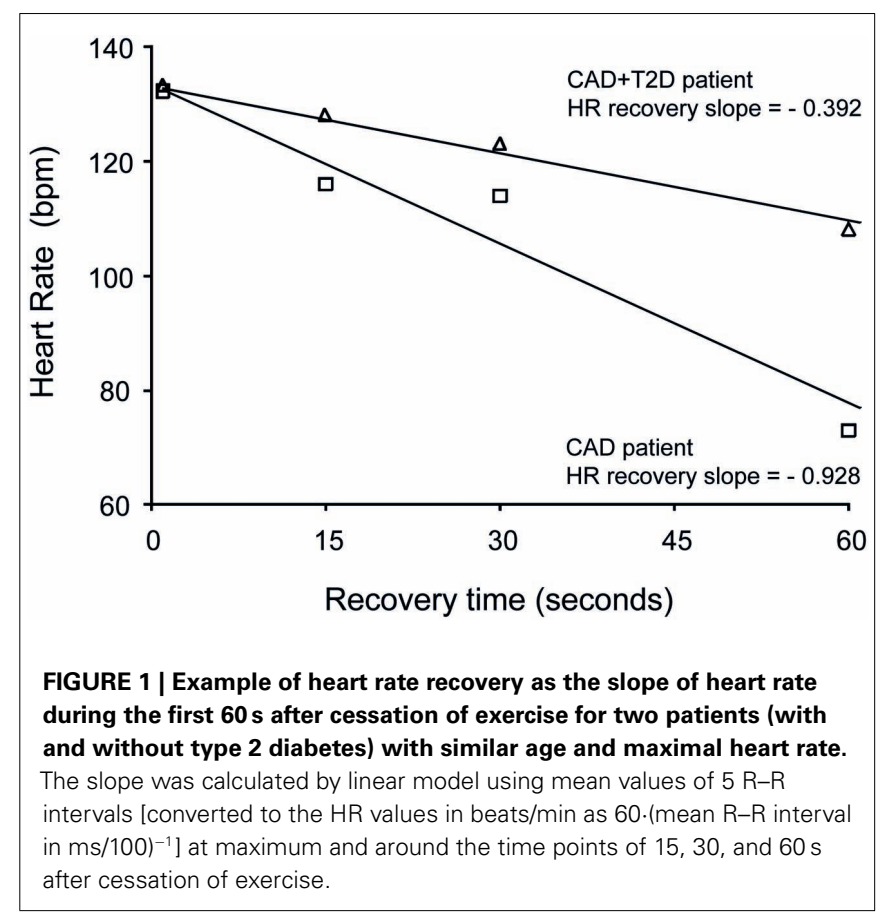


Polar R-R data), all of the R-R intervals were edited manually to exclude all premature beats and noise, which accounted for $<8 \%$ in every subject. ECG data was used during the editing to confirm sinus origin of the beats. An autoregressive model was used to estimate the power spectrum densities of HR variability after period level detrending (Huikuri et al., 1996; Tulppo et al., 1996). The power spectra were quantified by measuring the area under two frequency bands: LF power $(0.04-0.15 \mathrm{~Hz})$ and HF power $(0.15-0.4 \mathrm{~Hz})$. Details of the spectrum analyses have been described previously elsewhere (Task Force of the European Society of Cardiology and the North American Society of Pacing and Electrophysiology, 1996). Detrended fluctuation analysis (DFA) method was used to calculate fractal-like correlation properties of the R-R interval data (Peng et al., 1995; Iyengar et al., 1996). In this study the short-term (4-11 beats) scaling exponent $(\alpha-1)$ was calculated based on previous experiments (Mäkikallio et al., 1996).

\section{STATISTICS}

The data were presented as mean \pm SD. The normal Gaussian distribution of the data was verified with the Kolmogorov-Smirnov goodness-of-fit test $(z$ value $>1.0)$. For repeated measurements of post-exercise $\mathrm{HR}$ recovery $\left(\mathrm{HRR}_{15}, \mathrm{HRR}_{30}, \mathrm{HRR}_{60}, \mathrm{HRR}_{120}\right)$, two-factor ANOVA (time $\times$ group) was used to assess main effects followed by post hoc comparison (unpaired $t$-test). Significant post hoc differences in HR recovery between the groups were adjusted for maximal METs, BMI, and medications (calcium antagonists and nitrates) using ANCOVA. For other variables, the unpaired Student's $t$-test was used to assess the differences between $\mathrm{CAD}$ and $\mathrm{CAD}+\mathrm{T} 2 \mathrm{D}$ groups in normally distributed data. The Mann-Whitney $U$-test was used to assess the difference in HR variability indices between groups. The Chi-square test was used for categorical variables. The data were analyzed using SPSS software (SPSS 19.0, SPSS Inc., Chicago, USA). A $p$-value $<0.05$ was considered statistically significant.

\section{RESULTS}

\section{STUDY POPULATION}

The characteristics of the study population, including comparisons between diabetic and non-diabetic patients, are given in Table 1. The diabetic patients' body composition, e.g., weight $(p<0.001)$, waist circumference $(p<0.001)$, BMI $(p<0.001)$, and HbAlc $(p<0.001)$ differed from that of the non-diabetic patients. However, blood pressure, EF, history of infarction, and revascularization or smoking did not differ between the diabetic and non-diabetic patients (Table 1). Medication did not differ between the groups, except that calcium antagonists, nitrates, and antidiabetics were more common among the diabetic than the non-diabetic patients (Table $\mathbf{1}$ ).

\section{HR RESPONSE TO MAXIMAL EXERCISE}

The results of the maximal exercise test, including comparisons between diabetic and non-diabetic patients, are given in Table 2 . Maximal exercise capacity was lower $(p<0.001)$ in the diabetes patients, but maximal HR $(p=0.178)$ was at the same level compared with the non-diabetic patients (Table 2 ). HR reserve was smaller $(p=0.027)$ and CRI tended to be smaller $(p=0.057)$ in
Table 1 | Characteristics of patients.

\begin{tabular}{|c|c|c|c|}
\hline & CAD + T2D $(n=68)$ & $\operatorname{CAD}(n=64)$ & $p$-Level \\
\hline $\operatorname{Sex}(F / M)$ & $15 / 53$ & $13 / 51$ & $p=0.488$ \\
\hline Age (years) & $61 \pm 5$ & $62 \pm 5$ & $p=0.514$ \\
\hline Height $(\mathrm{cm})$ & $171 \pm 7$ & $171 \pm 8$ & $p=0.678$ \\
\hline Weight (kg) & $89 \pm 15$ & $80 \pm 12$ & $p<0.001$ \\
\hline Waist (cm) & $105 \pm 12$ & $94 \pm 10$ & $p<0.001$ \\
\hline Hip (cm) & $105 \pm 10$ & $99 \pm 6$ & $p<0.001$ \\
\hline Waist/Hip ratio & $1.00 \pm 0.07$ & $0.95 \pm 0.07$ & $p<0.001$ \\
\hline $\mathrm{BMI}\left(\mathrm{kg} \mathrm{m}^{-2}\right)$ & $30 \pm 4$ & $27 \pm 3$ & $p<0.001$ \\
\hline $\mathrm{HbA1c}(\%)$ & $6.0 \pm 0.7$ & $5.5 \pm 0.2$ & $p<0.001$ \\
\hline $\mathrm{SBP}(\mathrm{mmHg})$ & $138 \pm 18$ & $136 \pm 16$ & $p=0.672$ \\
\hline $\mathrm{DBP}(\mathrm{mmHg})$ & $82 \pm 10$ & $82 \pm 8$ & $p=0.875$ \\
\hline \multicolumn{4}{|l|}{ HISTORY OF AMI } \\
\hline NSTEMI & $18(26 \%)$ & $19(30 \%)$ & $P=0.469$ \\
\hline STEMI & $13(19 \%)$ & $14(21 \%)$ & $p=0.662$ \\
\hline \multicolumn{4}{|c|}{ REVASCULARIZATION } \\
\hline CAGB & $14(21 \%)$ & $13(28 \%)$ & $p=0.506$ \\
\hline $\mathrm{PCl}$ & $42(67 \%)$ & $27(59 \%)$ & $p=0.426$ \\
\hline Current smokers & $3(4 \%)$ & $8(12 \%)$ & $p=0.147$ \\
\hline $\operatorname{LVEF}(\%)$ & $67 \pm 8$ & $65 \pm 8$ & $p=0.107$ \\
\hline \multicolumn{4}{|l|}{ MEDICATION } \\
\hline Anticougulants & $66(97 \%)$ & $63(98 \%)$ & $p=1.000$ \\
\hline Beta blockers & $68(100 \%)$ & $64(100 \%)$ & $p=1.000$ \\
\hline Calcium antagonists & $20(29 \%)$ & $9(14 \%)$ & $p=0.037$ \\
\hline ACEI & $31(46 \%)$ & $23(36 \%)$ & $p=0.291$ \\
\hline AT2 & $13(19 \%)$ & $14(22 \%)$ & $p=0.830$ \\
\hline Diuretics & $26(38 \%)$ & $15(23 \%)$ & $p=0.090$ \\
\hline Statin & $63(93 \%)$ & $57(89 \%)$ & $p=0.553$ \\
\hline Insulines & $10(7 \%)$ & $0(0 \%)$ & $p=0.001$ \\
\hline Oral antidiabetics & $50(74 \%)$ & $0(0 \%)$ & $p<0.001$ \\
\hline Nitrates & $28(41 \%)$ & $8(13 \%)$ & $p<0.001$ \\
\hline Arrhythmia & $1(1 \%)$ & $1(1 \%)$ & $p=1.000$ \\
\hline
\end{tabular}

Values are mean $\pm S D$. BMI, body mass index; HbA1C, Glycosylated hemoglobin; SBP, systolic blood pressure; DBP, diastolic blood pressure; HR, heart rate; AMI, acute myocardial infarction; NSTEMI, no-ST segment elevation myocardial infarction; STEMI, ST segment elevation myocardial infarction; revascularized, the patients who had at least one of the procedures (CABG, coronary artery by-pass grafting or $\mathrm{PCl}$, Percutaneus coronary intervention); $L V E F$, left ventricular ejection fraction; $A C E l$, angiotensin conversion enzyme inhibitor; AT2, angiotensin II receptor blocker; $C A D$, coronary artery disease group; $C A D+T 2 D$, coronary artery disease with type 2 diabetes.

the diabetic patients than in the non-diabetic patients. However, there were not significant differences between groups in $\mathrm{HR}$ reserve or CRI after adjustment for maximal METs, BMI, and medication, e.g., for HR reserve ANCOVA $p=0.686, p<0.001, p=0.126$, and $p=0.169$ for diabetes, Mets, BMI, and calcium antagonists, respectively. There was no difference between the groups in the prevalence of ST segment depression $>0.1 \mathrm{mV}$ during the exercise test.

\section{HR RECOVERY}

Type 2 diabetes modified post-exercise HR recovery (main effect for time $\times$ group interaction $p=0.037$ ). The diabetic patients had 
Table 2 | Maximal exercise capacity and heart rate recovery.

\begin{tabular}{llll}
\hline & CAD +T2D $(\boldsymbol{n}=\mathbf{6 8})$ & CAD $(\boldsymbol{n}=\mathbf{6 4})$ & $\boldsymbol{p}$-Level \\
\hline Max load (W) & $139 \pm 41$ & $155 \pm 43$ & $p=0.033$ \\
Max METs & $6.5 \pm 1.7$ & $7.7 \pm 1.9$ & $p<0.001$ \\
MAX VO2PEAK & & & \\
$\mathrm{ml} \mathrm{kg}^{-1}$ min $^{-1}$ & $21.6 \pm 5.8$ & $25.9 \pm 6.5$ & $p<0.001$ \\
I min $^{-1}$ & $1.89 \pm 0.52$ & $2.05 \pm 0.58$ & $p=0.101$ \\
Max ST & $32(47 \%)$ & $57(49 \%)$ & $p=0.228$ \\
depression > 1 mm & & & \\
Max HR (bpm) & $128 \pm 19$ & $132 \pm 18$ & $p=0.178$ \\
HR reserve (bpm) & $70 \pm 20$ & $78 \pm 18$ & $p=0.027$ \\
CRI (bpm) & $69 \pm 18$ & $75 \pm 17$ & $p=0.057$ \\
HR RECOVERY & & & \\
15s (bpm) & $10.9 \pm 4.6$ & $10.8 \pm 5.0$ & $p=0.376$ \\
30 s (bpm) & $15.8 \pm 7.0$ & $17.8 \pm 6.9$ & $p=0.098$ \\
60 s (bpm) & $32.7 \pm 10.5$ & $37.8 \pm 9.7$ & $p=0.006$ \\
120 s (bpm) & $44.3 \pm 13.4$ & $48.9 \pm 11.1$ & $p=0.037$ \\
Slope 60 (beats/s) & $-0.53 \pm 0.17$ & $-0.62 \pm 0.14$ & $p=0.004$ \\
\hline
\end{tabular}

Values are mean $\pm S D$. METs, metabolic equivalents; $V O_{2}$ peak, peak uptake oxygen; HR, heart rate; CRI, maximal chronotropic response index.

delayed $\mathrm{HRR}_{60}(p=0.006), \mathrm{HRR}_{120}(p=0.037)$, and $\mathrm{HRR}_{\text {slope }}$ $(p=0.004)$ compared with the non-diabetic patients (Table 2). However, there were not significant differences between groups in $\mathrm{HRR}_{60}, \mathrm{HRR}_{120}$, or $\mathrm{HRR}_{\text {slope }}$ after adjustment for maximal METs, BMI, and medication, e.g., for $\mathrm{HRR}_{60}$ ANCOVA $p=0.223$, $p=0.061, p=0.387$, and $p=0.094$ for diabetes, Mets, BMI, and calcium antagonists, respectively. The corresponding $p$ values for HRR $_{120}$ were $p=0.980, p=0.001, p=0.451$, and $p=0.006$ and for $\mathrm{HRR}_{\text {slope }} p=0.228, p=0.030, p=0.404$, and $p=0.079$ for diabetes, Mets, BMI, and calcium antagonists, respectively. Nitrates did not modify HR behavior between groups at any condition. Examples of $\mathrm{HRR}_{\text {slope }}$ for non-diabetic and diabetic subjects are shown in Figure 1.

\section{HR AND HR VARIABILITY AT REST, DURING SUBMAXIMAL EXERCISE AND AFTER EXERCISE}

Heart rate and HR variability before and after exercise, including comparisons between diabetic and non-diabetic patients, are given in Table 3. Five diabetic patients were excluded from the analysis due to the significant number of extra systoles or technical artifacts in the R-R interval data. One non-diabetic patient was excluded due to the extra systoles in both pre- and post-exercise conditions and one in post-exercise condition due to the same reason.

The diabetic patients had a higher HR in resting condition than the non-diabetic patients $(p=0.030)$, but no other differences were observed at rest or in post-exercise condition (Table 3 ). HR or HR variability did not differ between the groups during submaximal exercise at the levels of 40,60 , or $80 \%$ of maximal oxygen uptake, e.g., $\mathrm{HR}$ was $92 \pm 12$ vs. $95 \pm 14 \mathrm{bpm}(p=0.099)$ and $\alpha_{1}$ $1.02 \pm 0.37$ vs. $1.02 \pm 0.32(p=0.93)$ at the level of $61 \pm 5 \%$ and $61 \pm 5 \%$ of maximal oxygen uptake for diabetic and non-diabetic patients, respectively.
Table 3 | Average values of linear and non-linear heart rate variability before exercise $(5 \mathrm{~min}$ ) and in post-exercise condition from 3 to $8 \mathrm{~min}$ after exercise, both in supine position.

\begin{tabular}{llll}
\hline & CAD +T2D & CAD & $\boldsymbol{p}$-Level \\
\hline Pre-exercise 5 min & $\boldsymbol{n}=\mathbf{6 3}$ & $\boldsymbol{n}=\mathbf{6 3}$ & \\
HR (bpm) & $57 \pm 10$ & $54 \pm 6$ & $p=0.030$ \\
SDNN (ms) & $36 \pm 19$ & $36 \pm 21$ & $p=0.969$ \\
HF power (ms ${ }^{2}$ ) & $299 \pm 353$ & $479 \pm 1347$ & $p=0.490$ \\
LF power $\left(\mathrm{ms}^{2}\right)$ & $385 \pm 521$ & $409 \pm 563$ & $p=0.940$ \\
LF/HF ratio & $1.81 \pm 1.71$ & $1.47 \pm 1.34$ & $p=0.210$ \\
$\alpha-1$ & $1.04 \pm 0.27$ & $0.99 \pm 0.26$ & $p=0.280$ \\
Post-exercise 5 min & $\boldsymbol{n}=\mathbf{6 3}$ & $\boldsymbol{n}=\mathbf{6 2}$ & \\
HR (bpm) & $76 \pm 10$ & $75 \pm 10$ & $p=0.765$ \\
SDNN (ms) & $29 \pm 12$ & $28 \pm 17$ & $p=0.386$ \\
HF power (ms ${ }^{2}$ ) & $102 \pm 172$ & $114 \pm 246$ & $p=0.268$ \\
LF power (ms ${ }^{2}$ ) & $162 \pm 212$ & $175 \pm 352$ & $p=0.608$ \\
LF/HF ratio & $2.8 \pm 2.3$ & $3.9 \pm 3.9$ & $p=0.257$ \\
$\alpha-1$ & $1.18 \pm 0.30$ & $1.24 \pm 0.28$ & $p=0.277$ \\
\hline
\end{tabular}

Values are mean $\pm S D$. HR, heart rate; $S D N N, S D$ of normal-to-normal $R-R$ intervals; $H F$, high frequency power of $R-R$ intervals; $L F$, low frequency power of $R-R$ intervals; $\alpha-1$, fractal scaling exponent of $R-R$ intervals.

\section{DISCUSSION}

The present study showed that post-exercise HR recovery was slower in CAD + T2D patients than in CAD patients, suggesting an impairment of vagal modulation and/or augmented sympathetic activity initially after exercise for diabetic patients. The impaired HR recovery in diabetic patients was the most obvious $1 \mathrm{~min}$ after exercise, documented by $\mathrm{HRR}_{60}$ and $\mathrm{HRR}_{\text {slope }}$ indices. However, blunted HR recovery initially after exercise in diabetic patients compared with non-diabetic patients was more closely related to low exercise capacity and obesity than to T2D itself. Taken together, these findings suggest that delayed HR recovery after exercise in T2D patients may be reversible through prevention and treatment, including, e.g., regular exercise and weight management.

\section{POST-EXERCISE HR DYNAMICS}

The interplay between sympathetic and vagal regulation of HR during exercise is organized in a reciprocal fashion, i.e., increased sympathetic activity is accompanied by decreased vagal activity in the heart during dynamic exercise (Robinson et al., 1966; Maciel et al., 1986; Orizio et al., 1988; Yamamoto and Hughson, 1991; Tulppo et al., 1996, 1998b). However, this reciprocal behavior is altered in the recovery phase after exercise due to temporal differences in the recovery pattern of the autonomic arms in postexercise condition (Tulppo et al., 2011). A rapid restoration of vagal activity occurs after cessation of exercise (Imai et al., 1994; Goldberger et al., 2006; Martinmaki and Rusko, 2008; Tulppo et al., 2011). On the contrary, the sympathetic nervous system seems to have a longer latency to return to the baseline after cessation of exercise, resulting in long-lasting hyperactivity of sympathetic activity (Ray, 1993; Tulppo et al., 2011). Taken together, these changes in autonomic regulation may result in dual activation of the sympathetic and vagal arms in post-exercise condition 
(Tulppo et al., 2011). These changes in autonomic activity in postexercise condition may partly explain the clinical findings, since particularly the recovery phase of exercise has been shown to be a vulnerable phase for various cardiovascular events (Siscovick et al., 1982, 1984; Albert et al., 2000; von Klot et al., 2008).

It is well known that $\mathrm{CAD}+\mathrm{T} 2 \mathrm{D}$ patients are at a higher risk for cardiac events than CAD patients without diabetes. Altered autonomic regulation in post-exercise condition is one potential mechanism, since slow HR recovery after exercise has also been associated with cardiovascular events in various clinical and subclinical populations (Cole et al., 1999; Lauer and Froelicher, 2002; Nissinen et al., 2003; Jouven et al., 2005). In the present study, HR recovery from 1 to $2 \mathrm{~min}$ after exercise was the only marker of autonomic activity separating diabetic and non-diabetic cardiac patients matched with age, sex, and EF all in optimal medications, including $\beta$-blockade. Since a complex interaction of autonomic regulation occurs in the initial phase after exercise, it is difficult to detect the difference in HR recovery between diabetic and non-diabetic patients due to impaired vagal activation or augmented sympathetic activation or both. Also circulating catecholamines have an important contribution for the sympathetic post-exercise hyperactivity (Krock and Hartung, 1992), but unfortunately we did not measure epinephrine or norepinephrine in the present study. Thirdly, as a novel finding of the present study, there were no differences between patients groups in HR recovery after adjustment for METs and BMI. These findings emphasized regular exercise training and weight management as potential treatments to improve post-exercise $\mathrm{HR}$ recovery in $\mathrm{CAD}+\mathrm{T} 2 \mathrm{D}$ patients. Importantly, also calcium antagonists modified HR recovery particularly $2 \mathrm{~min}$ after exercise. Patients with calcium antagonists usually have more severe hypertension which is associated with delayed HR recovery (Carnethon et al., 2011).

\section{HR RESPONSE TO MAXIMAL EXERCISE}

Measurement of the chronotropic response of $\mathrm{HR}$ to exercise has been used to assess particularly sympathetic influence on the heart and it has been shown to be a powerful predictor of cardiac mortality in both asymptomatic populations (Azarbal et al., 2004; Gulati et al., 2005; Jouven et al., 2005; Savonen et al., 2006; Kiviniemi et al., 2011) and in patients with various cardiac diseases (Myers et al., 2007; Savonen et al., 2008; Kiviniemi et al., 2011). In the present study HR reserve was lower and the maximal chronotropic response adjusted for age (CRI) tended to be lower in $\mathrm{CAD}+\mathrm{T} 2 \mathrm{D}$ patients than in CAD patients without diabetes. However, there were no differences between patients groups in these indices after adjustment for fitness and BMI.

\section{HR VARIABILITY}

Type 2 diabetes has been shown to decrease HR variability and baroreflex sensitivity in T2D patients without CAD (Masaoka et al., 1985; Frattola et al., 1997). There are previous studies where T2D has shown no additional decrease in baroreflex sensitivity among patients with CAD (Wykretowicz et al., 2005) or in HR variability among T2D patients with heart failure or CAD (Burger and Aronson, 2001; Kiviniemi et al., 2010). Also in the present study the short-term HR variability indices measured at resting or post-exercise condition were not able to separate CAD patients with and without T2D. There are several potential explanations for these findings. First, the populations are carefully matched according to age, sex, EF, and $\beta$-blockade which all are known to effect on HR variability and may partly explain the present findings. Secondly, short-term HR variability measures at laboratory condition are not so well reproducible than 24-h recordings (Huikuri et al., 1990; Tulppo et al., 1998b) and may be influenced by "white coat" effects in some subjects (Grassi et al., 1999). Thirdly, high level of circulating norepinephrine particularly in post-exercise condition may results in abrupt changes in beat-tobeat R-R interval dynamics which are not detected by used HR variability methods (Tulppo et al., 1998a). On the contrary to HR variability measurements at rest or few minutes after exercise, rapid and marked changes occurs in both autonomic arms in tens of seconds from sympathetic dominance to restoration of vagal activity resulting decreased HR after exercise (Tulppo et al., 2011). The unique behavior of autonomic regulation initially after maximal exercise is the major candidate to explain differences in HR recovery between diabetic and non-diabetic patient groups.

\section{STUDY LIMITATIONS}

The measurements of the present study were performed under continued prescribed medication because of ethical reasons and the well known withdrawal effect of beta-block cessation. However, the present results will have more practical implications when the analyses are performed at a time when the patients are on their normal medication.

\section{CLINICAL APPLICATIONS}

Based on the present study, it is important to emphasize the role of physical exercise in maintaining good cardiovascular function, improving physical performance, and losing weight. Although all the patients were on optimized medication, it is important to underscore that behavioral modification, exercises, and diet should be given priority similar to other preventive medications (Chow et al., 2010).

\section{CONCLUSION}

Heart rate recovery $1 \mathrm{~min}$ after exercise is the most powerful index separating CAD patients with and without T2D in the modern treatment era, beyond short-term $H R$ variability measurements at rest, during exercise, or in post-exercise condition. HR recovery is delayed in CAD + T2D patients compared with CAD patients without T2D, suggesting impairment of vagal activity and/or augmented sympathetic activity after exercise. However, blunted HR recovery initially after exercise in diabetic patients compared with non-diabetic patients is more closely related to exercise capacity and obesity than to T2D itself.

\section{ACKNOWLEDGMENTS}

This work was supported by grants from the Finnish Technology Development Centre (TEKES. Helsinki. Finland), Paavo Nurmi Foundation, Turku, Finland, Polar Electro Oy, Kempele, Finland and Hur Oy, Kokkola, Finland, and the National Council for Scientific and Technological Development, Brasília, Brazil. (proc. 200630/2010-5). 


\section{REFERENCES}

Albert, C. M., Mittleman, M. A., Chae, C. U., Lee, I. M., Hennekens, C. H., and Manson, J. E. (2000). Triggering of sudden death from cardiac causes by vigorous exertion. N. Engl. J. Med. 343, 1355-1361.

Azarbal, B., Hayes, S. W., Lewin, H. C., Hachamovitch, R., Cohen, I., and Berman, D. S. (2004). The incremental prognostic value of percentage of heart rate reserve achieved over myocardial perfusion singlephoton emission computed tomography in the prediction of cardiac death and all-cause mortality: superiority over $85 \%$ of maximal agepredicted heart rate. J. Am. Coll. Cardiol. 44, 423-430.

Burger, A. J., and Aronson, D. (2001). Effect of diabetes mellitus on heart rate variability in patients with congestive heart failure. Pacing Clin. Electrophysiol. 24, 53-59.

Carnethon, M. R., Sternfeld, B., Liu, K., Jacobs, D. R. Jr., Schreiner, P. J., Williams, O. D., Lewis, C. E., and Sidney, S. (2011). Correlates of heart rate recovery over 20 years in a healthy population sample. Med. Sci. Sports Exerc. doi: 10.1249/MSS.0b013e31822cb190. [Epub ahead of print].

Chow, C. K., Jolly, S., Rao-Melacini, P., Fox, K. A., Anand, S. S., and Yusuf, S. (2010). Association of diet, exercise, and smoking modification with risk of early cardiovascular events after acute coronary syndromes. Circulation 121, 750-758.

Cole, C. R., Blackstone, E. H., Pashkow, F. J., Snader, C. E., and Lauer, M. S. (1999). Heart-rate recovery immediately after exercise as a predictor of mortality. N. Engl. J. Med. 341, 1351-1357.

Cole, C. R., Foody, J. M., Blackstone, E. H., and Lauer, M. S. (2000). Heart rate recovery after submaximal exercise testing as a predictor of mortality in a cardiovascularly healthy cohort. Ann. Intern. Med. 132, 552-555.

Coumel, P. (1994). Paroxysmal atrial fibrillation: a disorder of autonomic tone? Eur. Heart J. 15(Suppl. A), 9-16.

Frattola, A., Parati, G., Gamba, P., Paleari, F., Mauri, G., Di Rienzo, M., Castiglioni, P., and Mancia, G. (1997). Time and frequency domain estimates of spontaneous baroreflex sensitivity provide early detection of autonomic dysfunction in diabetes mellitus. Diabetologia 40, 1470-1475.

Fu, Q., Levine, B. D., Pawelczyk, J. A., Ertl, A. C., Diedrich, A., Cox, J. F., Zuckerman, J. H., Ray, C. A., Smith, M. L., Iwase, S., Saito, M., Sugiyama,
Y., Mano, T., Zhang, R., Iwasaki, K., Lane, L. D., Buckey, J. C. Jr., Cooke, W. H., Robertson, R. M., Baisch, F. J., Blomqvist, C. G., Eckberg, D. L., Robertson, D., and Biaggioni, I. (2002). Cardiovascular and sympathetic neural responses to handgrip and cold pressor stimuli in humans before, during and after spaceflight. J. Physiol. (Lond.) 544, 653-664.

Goldberger, J. J., Le, F. K., Lahiri, M., Kannankeril, P. J., Ng, J., and Kadish, A. H. (2006). Assessment of parasympathetic reactivation after exercise. Am. J. Physiol. Heart Circ. Physiol. 290, H2446-H2452.

Grassi, G., Turri, C., Vailati, S., Dell'oro, R., and Mancia, G. (1999). Muscle and skin sympathetic nerve traffic during the "white-coat" effect. Circulation 100, 222-225.

Gregoire, J., Tuck, S., Yamamoto, Y., and Hughson, R. L. (1996). Heart rate variability at rest and exercise: influence of age, gender, and physical training. Can. J. Appl. Physiol. 21, 455-470.

Gulati, M., Black, H. R., Shaw, L. J., Arnsdorf, M. F., Merz, C. N., Lauer, M. S., Marwick, T. H., Pandey, D. K., Wicklund, R. H., and Thisted, R. A. (2005). The prognostic value of a nomogram for exercise capacity in women. N. Engl. J. Med. 353, 468-475.

Haffner, S. M., Lehto, S., Rönnemaa, T., Pyorälä, K., and Laakso, M. (1998). Mortality from coronary heart disease in subjects with type 2 diabetes and in nondiabetic subjects with and without prior myocardial infarction. N. Engl. J. Med. 339, 229-234.

Huikuri, H. V. (2008). Heart rate dynamics as a marker of vulnerability to atrial fibrillation. J. Cardiovasc. Electrophysiol. 19, 913-914.

Huikuri, H. V., Kessler, K. M., Terracall, E., Castellanos, A., Linnaluoto, M. K., and Myerburg, R. J. (1990). Reproducibility and circadian rhythm of heart rate variability in healthy subjects. Am. J. Cardiol. 65, 391-393.

Huikuri, H. V., Seppanen, T., Koistinen, M. J., Airaksinen, J., Ikaheimo, M. J., Castellanos, A., and Myerburg, R. J. (1996). Abnormalities in beat-to-beat dynamics of heart rate before the spontaneous onset of life-threatening ventricular tachyarrhythmias in patients with prior myocardial infarction. Circulation 93, 1836-1844.

Imai, K., Sato, H., Hori, M., Kusuoka, H., Ozaki, H., Yokoyama, H., Takeda, H., Inoue, M., and Kamada, T. (1994). Vagally mediated heart rate recovery after exercise is accelerated in athletes but blunted in patients with chronic heart failure. J. Am. Coll. Cardiol. 24, 1529-1535.

Iyengar, N., Peng, C. K., Morin, R. Goldberger, A. L., and Lipsitz, L. A. (1996). Age-related alterations in the fractal scaling of cardiac interbeat interval dynamics. Am. J. Physiol. 271, R1078-R1084.

Jouven, X., and Ducimetiere, P. (2000). Recovery of heart rate after exercise. N. Engl. J. Med. 342, 662-663.

Jouven, X., Empana, J. P., Schwartz, P. J., Desnos, M., Courbon, D., and Ducimetiere, P. (2005). Heart-rate profile during exercise as a predictor of sudden death. N. Engl. J. Med. 352, 1951-1958.

Junttila, M. J., Barthel, P., Myerburg, R. J., Makikallio, T. H., Bauer, A., Ulm, K., Kiviniemi, A., Tulppo, M., Perkiomaki, J. S., Schmidt, G. and Huikuri, H. V. (2010). Sudden cardiac death after myocardial infarction in patients with type 2 diabetes. Heart Rhythm 7, 1396-1403.

Kiviniemi, A. M., Tiinanen, S., Hautala, A. J., Seppanen, T., Norton, K. N. Frances, M. F., Nolan, R. P., Huikuri, H. V., Tulppo, M. P., and Shoemaker, J. K. (2010). Low-frequency oscillations in R-R interval and blood pressure across the continuum of cardiovascular risk. Auton. Neurosci. 158 92-99.

Kiviniemi, A. M., Tulppo, M. P., Hautala, A. J., Makikallio, T. H., Perkiomaki, J. S., Seppanen, T., and Huikuri, H. V. (2011). Long-term outcome of patients with chronotropic incompetence after an acute myocardial infarction. Ann. Med. 43, 33-39.

Kleiger, R. E., Miller, J. P., Bigger, J. T. Jr., and Moss, A. J. (1987). Decreased heart rate variability and its association with increased mortality after acute myocardial infarction. Am. J. Cardiol. 59, 256-262.

Krock, L. P., and Hartung, G. H. (1992). Influence of post-exercise activity on plasma catecholamines, blood pressure and heart rate in normal subjects. Clin. Auton. Res. 2, 89-97.

Lanza, G. A., Barone, L., Scalone, G., Pitocco, D., Sgueglia, G. A., Mollo, R., Nerla, R., Zaccardi, F., Ghirlanda, G., and Crea, F. (2011). Inflammation-related effects of adjuvant influenza A vaccination on platelet activation and cardiac autonomic function. J. Intern. Med. 269, 118-125.

Lauer, M. S., and Froelicher, V. (2002). Abnormal heart-rate recovery after exercise. Lancet 360, 1176-1177.

Maciel, B. C., Gallo, L. Jr., Marin Neto, J. A., Lima Filho, E. C., and Martins, L. E. (1986). Autonomic nervous control of the heart rate during dynamic exercise in normal man. Clin. Sci. 71 457-460.

Mäkikallio, T. H., Seppänen, T., Niemelä, M., Airaksinen, K. E., Tulppo, M., and Huikuri, H. V. (1996). Abnormalities in beat to beat complexity of heart rate dynamics in patients with a previous myocardial infarction. J. Am. Coll. Cardiol. 28, 1005-1011.

Martinmaki, K., and Rusko, H. (2008). Time-frequency analysis of heart rate variability during immediate recovery from low and high intensity exercise. Eur. J. Appl. Physiol. 102, 353-360.

Masaoka, S., Lev-Ran, A., Hill, L. R., Vakil, G., and Hon, E. H. (1985). Heart rate variability in diabetes: relationship to age and duration of the disease. Diabetes Care 8, 64-68.

Montano, N., Ruscone, T. G., Porta, A., Lombardi, F., Pagani, M., and Malliani, A. (1994). Power spectrum analysis of heart rate variability to assess the changes in sympathovagal balance during graded orthostatic tilt. Circulation 90, 1826-1831.

Myers, J., Tan, S. Y., Abella, J., Aleti, V., and Froelicher, V. F. (2007). Comparison of the chronotropic response to exercise and heart rate recovery in predicting cardiovascular mortality. Eur. J. Cardiovasc. Prev. Rehabil. 14, 215-221.

Nissinen, S. I., Makikallio, T. H., Seppanen, T., Tapanainen, J. M., Salo, M., Tulppo, M. P., and Huikuri, H. V. (2003). Heart rate recovery after exercise as a predictor of mortality among survivors of acute myocardial infarction. Am. J. Cardiol. 91, 711-714.

Okada, N., Takahashi, N., Yufu, K. Murozono, Y., Wakisaka, O., Shinohara, T., Anan, F., Nakagawa, M., Hara, M., Saikawa, T., and Yoshimatsu, H. (2010). Baroreflex sensitivity predicts cardiovascular events in patients with type 2 diabetes mellitus without structural heart disease. Circ. J. 74, 1379-1383.

Orizio, C., Perini, R., Comande, A., Castellano, M., Beschi, M., and Veicsteinas, A. (1988). Plasma catecholamines and heart rate at the beginning of muscular exercise in man. Eur. J. Appl. Physiol. Occup. Physiol. 57, 644-651.

Pagani, M., Furlan, R., Lombardi, F., Pizzinelli, P., Lanzi, G., Castelli, P., Cerutti, S., Santoli, C., and Malliani, A. (1985). Technique for 24 hour recording of continuous high fidelity arterial pressure and electrocardiogram in ambulatory patients. Clin. Exp. Hypertens. A 7, 401-405. 
Peng, C. K., Havlin, S., Stanley, H. E., and Goldberger, A. L. (1995). Quantification of scaling exponents and crossover phenomena in nonstationary heartbeat time series. Chaos $5,82-87$.

Piira, O. P., Huikuri, H. V., and Tulppo, M. P. (2011). Effects of emotional excitement on heart rate and blood pressure dynamics in patients with coronary artery disease. Auton. Neurosci. 160, 107-114.

Pop-Busui, R., Evans, G. W., Gerstein, H. C., Fonseca, V., Fleg, J. L., Hoogwerf, B. J., Genuth, S., Grimm, R. H., Corson, M. A., and Prineas, R. (2010). Effects of cardiac autonomic dysfunction on mortality risk in the action to control cardiovascular risk in diabetes (ACCORD) trial. Diabetes Care 33, 1578-1584.

Ray, C. A. (1993). Muscle sympathetic nerve responses to prolonged onelegged exercise. J. Appl. Physiol. 74, 1719-1722.

Robinson, B. F., Epstein, S. E., Beiser, G. D., and Braunwald, E. (1966). Control of heart rate by the autonomic nervous system. Studies in man on the interrelation between baroreceptor mechanisms and exercise. Circ. Res. 19, 400-411.

Savonen, K. P., Kiviniemi, V., Laukkanen, J. A., Lakka, T. A., Rauramaa, T. H., Salonen, J. T., and Rauramaa, R. (2008). Chronotropic incompetence and mortality in middle-aged men with known or suspected coronary heart disease. Eur. Heart J. 29, 1896-1902.

Savonen, K. P., Lakka, T. A., Laukkanen, J. A., Halonen, P. M., Rauramaa, T. H., Salonen, J. T., and Rauramaa, R. (2006). Heart rate response during exercise test and cardiovascular mortality in middle-aged men. Eur. Heart J. 27, 582-588.

Siscovick, D. S., Weiss, N. S., Fletcher, R. H., and Lasky, T. (1984). The incidence of primary cardiac arrest during vigorous exercise. N. Engl. J. Med. 311, 874-877.

Siscovick, D. S., Weiss, N. S., Hallstrom, A. P., Inui, T. S., and Peterson, D. R. (1982). Physical activity and primary cardiac arrest. JAMA 248, 3113-3117.

Smith, L. L., Kukielka, M., and Billman, G. E. (2005). Heart rate recovery after exercise: a predictor of ventricular fibrillation susceptibility after myocardial infarction. Am. J. Physiol. Heart Circ. Physiol. 288, H1763H1769.

Task Force of the European Society of Cardiology and the North American Society of Pacing and Electrophysiology. (1996). Heart rate variability. Standards of measurement, physiological interpretation, and clinical use. Eur. Heart J. 17, 354-381.

Tulppo, M. P., Hughson, R. L., Makikallio, T. H., Airaksinen, K. E., Seppanen, T., and Huikuri, H. V. (2001). Effects of exercise and passive head-up tilt on fractal and complexity properties of heart rate dynamics. Am. J. Physiol. Heart Circ. Physiol. 280, H1081-H1087.

Tulppo, M. P., Kiviniemi, A., Hautala, A. J., Kallio, M., Seppänen, T., Tiinanen, S., Mäkikallio, T. H., and Huikuri, H. (2011). Sympatho-vagal interaction in the recovery phase of exercise. Clin. Physiol. Funct. Imaging 31, 272-281.

Tulppo, M. P., Kiviniemi, A. M., Hautala, A. J., Kallio, M., Seppanen,
T., Makikallio, T. H., and Huikuri, H. V. (2005). Physiological background of the loss of fractal heart rate dynamics. Circulation 112 , 314-319.

Tulppo, M. P., Makikallio, T. H., Seppanen, T., Airaksinen, J. K., and Huikuri, H. V. (1998a). Heart rate dynamics during accentuated sympathovagal interaction. Am. J. Physiol. 274, H810-H816.

Tulppo, M. P., Makikallio, T. H., Seppanen, T., Laukkanen, R. T., and Huikuri, H. V. (1998b). Vagal modulation of heart rate during exercise: effects of age and physical fitness. Am. J. Physiol. 274, H424-H429.

Tulppo, M. P., Makikallio, T. H., Takala, T. E., Seppanen, T., and Huikuri, H. V. (1996). Quantitative beat-tobeat analysis of heart rate dynamics during exercise. Am. J. Physiol. 271, H244-H252.

von Klot, S., Mittleman, M. A., Dockery, D. W., Heier, M., Meisinger, C., Hormann, A., Wichmann, H. E., and Peters, A. (2008). Intensity of physical exertion and triggering of myocardial infarction: a case-crossover study. Eur. Heart J.29, 1881-1888.

WHO. (1999). Definition, diagnosis and classification of diabetes mellitus and its complications, part 1: diagnosis and classification of diabetes mellitus. Geneva: WHO.

Wykretowicz, A., Guzik, P., Bartkowiak, G., Krauze, T., Kasinowski, R., Dziarmaga, M., Wesseling, K. H., and Wysocki, H. (2005). Endothelial function and baroreflex sensitivity according to the oral glucose tolerance test in patients with coronary artery disease and normal fasting glucose levels. Clin. Sci. 109, 397-403.

Yamamoto, Y., and Hughson, R. L. (1991). Coarse-graining spectral analysis: new method for studying heart rate variability. J. Appl. Physiol. 71, 1143-1150.

Yamamoto, Y., Hughson, R. L., and Peterson, J. C. (1991). Autonomic control of heart rate during exercise studied by heart rate variability spectral analysis. J. Appl. Physiol. 71, 1136-1142.

Conflict of Interest Statement: The authors declare that the research was conducted in the absence of any commercial or financial relationships that could be construed as a potential conflict of interest.

Received: 09 June 2011; accepted: 18 August 2011; published online: 05 September 2011

Citation: Neves VR, Kiviniemi AM, Hautala AJ, Karjalainen J, Piira O-P, Catai AM, Mäkikallio TH, Huikuri HV and Tulppo MP (2011) Heart rate dynamics after exercise in cardiac patients with and without type 2 diabetes. Front. Physio. 2:57. doi: 10.3389/fphys.2011.00057

This article was submitted to Frontiers in Clinical and Translational Physiology, a specialty of Frontiers in Physiology.

Copyright (c) 2011 Neves, Kiviniemi, Hautala, Karjalainen, Piira, Catai, Mäkikallio, Huikuri and Tulppo. This is an open-access article subject to a nonexclusive license between the authors and Frontiers Media SA, which permits use, distribution and reproduction in other forums, provided the original authors and source are credited and other Frontiers conditions are complied with. 